\title{
Demystifying Assessment: The Road To Accreditation
}

Blaine T. Garfolo, Northwestern Polytechnic University, United States

Barbara L'Huillier, Prince Mohammad Bin Fahd University, Saudi Arabia

\begin{abstract}
Accreditation serves as both a quality assurance and accountability mechanism for our learning institutions. It is a voluntary process of self-regulation and non-governmental peer review supported, in general, by providers of tertiary education and examines the philosophy, goals, programs, facilities, resources, and financial viability of the institution. The culture of assessment and the information it generates should be embedded effectively within all institutional systems. This would enable an organization to focus their attention on the assumptions they make with respect to student learning and to promote a culture of continuous assessment and improvement in order to elevate students' quality of learning. It is through a process of programmatic assessment that evidence is gathered to support an application for accreditation to an appropriate accrediting agency.
\end{abstract}

What is driving the assessment movement in higher education? How do accreditation bodies make their decisions? What is the precise basis for accreditation? For example, what filtering process does accreditation bodies use when determining what evidence is or is not relevant when arriving at the final accreditation decision. Presumably, as in courts of law, there must be some mechanism or pre-defined criteria in which evidence is weighed and an appropriate decision is reached. Unfortunately, the mechanism is poorly understood by educational institutions and faculty alike. However, the standards of almost all accreditors include the expectation that institutions clearly state student learning outcomes (SLOs) and to assess those outcomes. Although there are a variety of academic accrediting bodies their policies and approaches tend to be more alike than different and appear to share similar expectations for the assessment of SLOs.

The key is the Assessment of Student Learning and it is a critical issue for students, teachers, curriculum designers, the accreditation process, quality assurance, and review of courses. How a student learns (student learning styles) and what they actually do learn (subject material) are often driven by the assessment required for a course of study.

Assessment is an ongoing, continuing improvement process aimed at understanding and elevating student learning. Assessment involves:

1. Having clear, explicit and transparent expectations for both the student and the institution.

2. Setting the criteria for learning at an appropriate level to demonstrate quality of learning.

3. Gathering, analyzing, and reflecting on the evidence in a systematic way to determine if student learning has occurred to the depth and breadth stated.

4. Using the information gathered to document, explain, and elevate student learning.

The purpose of this paper is to present a 'roadmap to assessment' that, if followed, will assist an organization in presenting themselves in the best possible light in order to gain accreditation. As methodology proceeds and ultimately provides the guiding strategy for the design and selection of methods used in the assessment process, the authors will present a methodology that will ensure that the assessment process is effective and successful. The authors will identify and analyze 
practices necessary to present a clear and concise body of work to an accreditation body. The authors will discuss the required elements involved in assessment in education and how to use assessment effectively as a means of maintaining both academic standards and enhancing the quality of the student learning experience.

Keywords: Programmatic Assessment; Student Learning Outcomes; Rubrics

\section{INTRODUCTION}

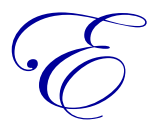

ducational values are the cornerstone of the student learning process and as such these values need to be clearly articulated to ensure that an inclusive and transparent process of learning assessment can take place. It is important for all parties to realize that learning is a longitudinal multi-dimensional integrated process. As such it requires the development and implementation of a culture of continuous assessment across the academic community which, if conducted correctly, will lead to the improvement of the student learning process. This necessitates in not only having clear and explicitly stated purposes, but also directing attention to the experiences and outcomes of the learning process. Assessment must promote change not only from within the classroom, but throughout the administrative structure in order to meet the responsibilities that a university has to both the student (the university's product) and the public (the university's client).

This paper contains a methodology that will assist those who are seeking accreditation for their tertiary institutions. It will identify and analyze practices that need to be followed in order to present a clear and concise body of work to an accreditation body and will discuss the elements involved in education assessment. In addition, it will demonstrate how to use assessment effectively as a means of maintaining both academic standards and enhancing the quality of the student learning experience.

First it will identify why it is important to assess student learning before defining the process of academic assessment. Then it will provide a detailed examination of program-based accreditation and the steps involved in the process. Next, it will specifically state who is responsible for what in terms of developing an assessment process and the role of the Office of Assessment. What follows next is a detailed examination of assessment methodology involving the identification and examination of the key components of the assessment process using a revised version of Bloom's (1956) taxonomy of educational objectives and goals. Finally, building on the work of Huba and Freed (2000) this paper will provide a step-by-step guide on how to complete the assessment process before providing concluding comments.

\section{Why Is Assessment Of Student Learning Important?}

In the authors' experiences, most 'good' teachers (admittedly a very subjective assessment) are constantly evaluating themselves and their students to determine what worked well and what did not in terms of getting the learning objective across to the students. Constant self-evaluation/assessment allows you to adjust curriculum delivery methods to help your students' learning process. However, this is a very informal, very personal, private and voluntary form of assessment. Accreditation, conversely, needs a more 'formalized' assessment of student learning as formal assessment allows you to make your informal activities more public, transparent, and systematic (Hutchings, 2010).

Student learning improvement is at the heart of assessment. When faculty are directly involved in the assessment process they can take ownership of the process, and in doing so gain many intrinsic and extrinsic benefits from their participation including a sense of personal and professional satisfaction at successful outcomes.

The three questions that must be asked at the start of any assessment process are:

1. What should students be learning?

2. What are students actually learning?

3. What should you, the instructor, be doing to facilitate student learning? 
Ultimately, assessment (for accreditation) is conducted to bring about improvement at all levels from course-to-program-to-the-institution. This is accomplished by establishing clear and measureable outcomes of student learning and by documenting and demonstrating that student learning has occurred. Through the process of assessment, evidence is generated to show that students have multiple opportunities to reach the specified outcomes that have been established. Finally, assessment reveals if students are learning what they have been taught or, if what they are being taught is what they need to learn. This is an important distinction sometimes lost on administrators and faculty alike. Assessment is not simply a box-ticking exercise. Rather it is a mechanism that, with skillful application, can be utilized to determine how effective and how successful programs and students are.

There are two basic types of accreditation: Institutional and Specialized. With institutional accreditation, the accrediting body looks at the institution in its entirety. With respect to specialized accreditation, there are a multitude of accreditation bodies depending on the area of specialization - each responsible for accrediting program quality in their area of specialization. Currently, there are more than 50 fields of specialization. As noted by AliMohamed (2008) specialization accreditation standards are above those required for institutional accreditation.

In the United States, there are six regional accrediting agencies:

1. Middle States Association of Colleges and Schools

2. New England Association of Schools and Colleges

3. The Higher Learning Commission-North Central Association of Colleges and Schools

4. $\quad$ Northwest Commission on Colleges and Universities

5. Southern Association of Colleges and Schools

6. Accrediting Commission for Senior Colleges and Universities and Accrediting Commission for Community and Junior Colleges-Western Association of Schools and Colleges.

Each is wholly responsible for accrediting institutions in their region and ensuring that their programs properly contribute to the objectives of the respective institutions and meets the agency's standards for educational quality.

\section{How To Define The Process Of Academic Assessment}

As noted by L'Huillier (2012, p 125) "Every word in every language is necessarily endowed with meaning" and rarely does the use of language conform to a standard of exactness and such is the case of the word 'assessment'. The word 'assessment' has taken on a multitude of meanings in our education system ranging from faculty grading to standardized tests to academic portfolios. The varied used of the word 'assessment' amongst tertiary education providers clearly indicates that as a whole, many different definitions of 'assessment' are held. For the purposes of this paper, and building on the work of Walvoord and Anderson (2011), the authors define the term 'assessment' to mean: the underlying methodology that provides the guiding strategy for the design and selection of methods used in the systematic collection and processing of data into information for the express purpose of analyzing and utilizing this information to improve student learning.

\section{What Is Program-Based Assessment?}

As noted by the American Association for Higher Education (1998), assessment is used to provide the body of data and evidence required by external accreditation bodies to support assertions made about academic programs with respect to their strengths and weaknesses. The intended purpose of developing an assessment strategy is threefold:

1. To improve student learning outcomes (SLOs)

2. To inform all relevant parties of any issues that can impact programs and student learning

3. To provide a plan for correcting any shortcomings in student learning or showcase successful plans as exemplars for other programs. 
With respect to assessment of programs, programmatic assessment should focus on the student learning experience. The authors concur with Kuh and Ikenberry's (2009) view that assessment results are integral to Academic Quality Management. Programmatic assessment is concerned with core knowledge, competencies, and requisite skills necessary for success in the students' chosen program of study. The focus of programmatic assessment is to document and convey to all parties the following:

1. What is it you are trying to accomplish?

2. How well or close are you to accomplishing it?

3. What can you do (if anything) to improve?

In conducting programmatic assessment effort must be made to ensure that it is faculty-designed and driven not administration-designed and driven particularly as accreditation bodies stress faculty involvement. Additionally, programmatic assessment should start and flow from a program's mission statement. Indeed, all faculty members should be able to discuss what their programs' mission statements are and how they are linked to student learning. It should be stressed that programmatic assessment focuses on groups of students not on individual students or individual faculty members. Finally, programmatic assessment is continuous and cumulative and should be carried out in a systematic way with the data stored, processed and evaluated over time for trend analysis. Refer to Figure 1 for a diagram of the relationship between elements of the culture of evidence and the assessment process.

Figure 1. Assessment And The Culture Of Evidence

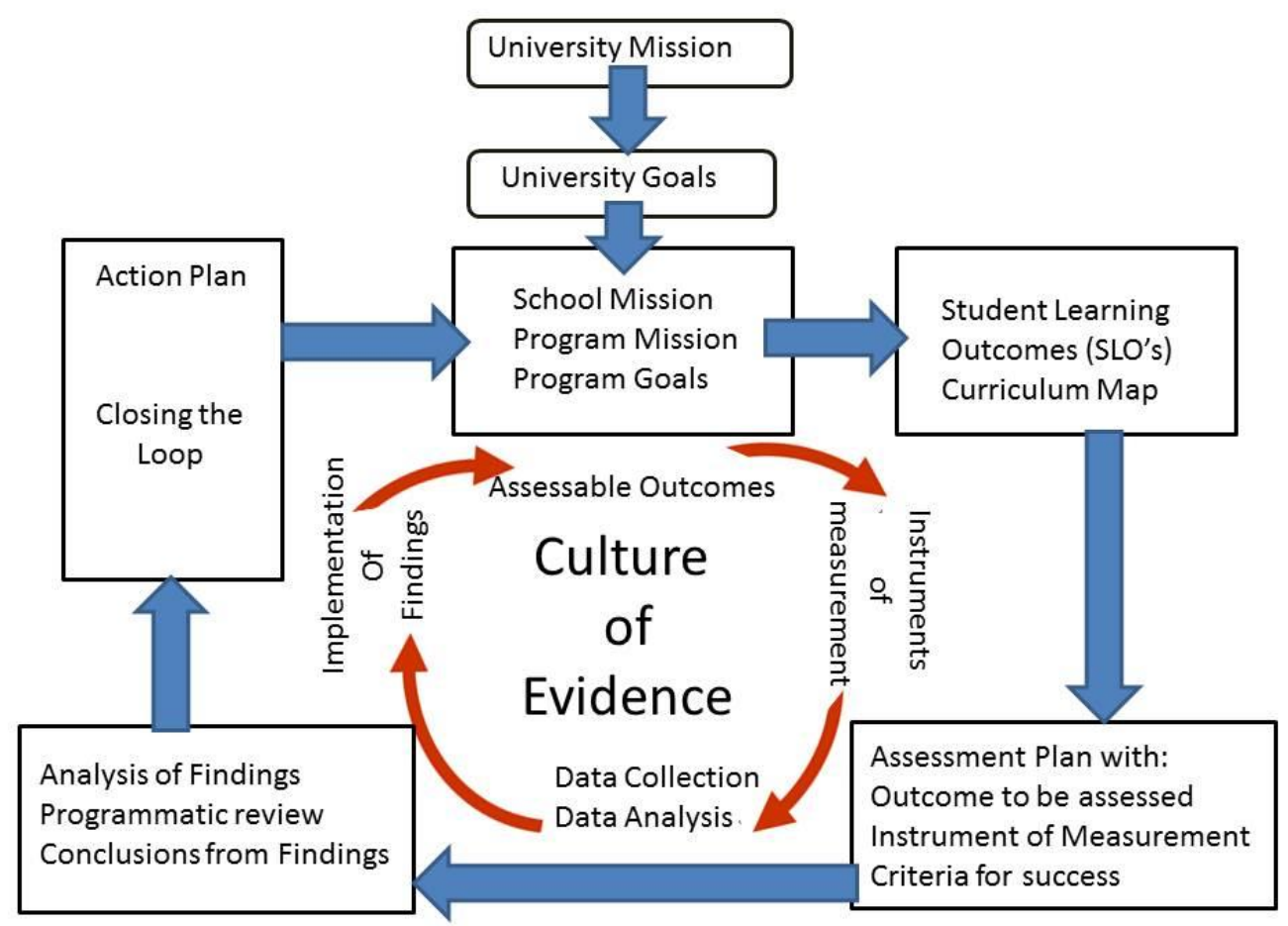

\section{What Are The Basic Steps Involved In The Assessment Process?}

Conceptually, there are six basic steps that guide an assessment process.

Identify In Broad Terms What Learning Outcomes Are Valued (Only A Single Value Per Outcome)

In this first step create student learning outcomes that reflect the core knowledge of the program. In their development, care should be given to capitalize on the depth and breadth of knowledge held by faculty in order to 
shape the focus and direction of the program. In the definition of the student learning objectives it is necessary to specify any activity or performance that needs to be measured and evaluated along with the criteria for success of each particular objective. This must be stated in such a way as to clearly and definitively state what the student is to know and understand as well as be able to accomplish at course completion. In creating student learning outcomes:

1. Focus on a small number of critical outcomes - what are the four or five most crucial outcomes for the program?

2. Identify a single result per outcome ensuring that the result should be reasonably obtainable.

3. Check that the outcome is linked to the mission statement of the program.

4. Determine specific skills or abilities that are required to be demonstrated by a student. That is, what are the most important things that students need to accomplish? Are there topic areas they struggle with on a regular basis?

5. $\quad$ Define the skills and knowledge students will need after they graduate.

6. Make sure the student learning outcomes are centered not on what they are going to be taught but rather on what the student will do.

SLOs need to be stated as an activity, product, or performance that can be measured. The authors concur with Ivanovski, Milenkovski, Ivanovska, and Kozuharov (2013) that SLOs should reflect higher order thinking skills (not introductory knowledge/skills) and be meaningful to the discipline.

\section{Articulate Multiple Measurable Outcomes For Each Learning Outcome}

The second stage in the process requires a shift in focus from intended results (as specified in student learning outcomes) to the achieved results (what you use to determine if the outcomes were met). The emphasis of learning outcomes is on the knowledge, skills, and abilities that students should possess after the completion of the course or program. The authors agree with Miville, Gelso, Pannu, Liu, Touradji, Holloway, and Fuertes (1999) that outcome measures center on the specific methods and tools responsible for generating and processing the data to produce information related to students' performance in accordance with learning outcomes.

In measuring the success or failure of SLOs, it is best to use multiple methods of measurement as this allows for the evaluation of student learning in a more comprehensive and effective manner. This is particularly important as many SLOs will be difficult to assess using only one measure. Furthermore, utilizing only a single measure could also result in misinformation about the learning outcome as a single measure tends to evaluate (rather than assess) a single dimension of a single phenomenon.

As students learn in different ways, so too do they respond in different ways depending on the evaluation tools. By using a multitude of evaluation tools, a more accurate picture of student learning and growth can emerge and be documented thereby increasing your confidence level with respect to programmatic changes and the learning process. Major advantages to using multiple evaluation tools include:

1. The ability to assess different component parts of a complex task.

2. Greater accuracy is achieved when multiple methods of assessment are used to produce a finding.

Multiple measures of assessment provide the comprehensive view required to determine if student learning is actually being achieved as specified by SLOs. This should be accomplished by using both quantitative and qualitative measures in the assessment methods. Quantitative measures provide numerical evidence of student learning while qualitative measures provide descriptive evidence; combined they provide a more complete picture of student learning.

\section{Collect Data To Assess How Well Students Meet Identified Objectives}

The third step in the process revolves around methods in data collection, specifically the gathering of student work/information. If conclusions are to be considered valid or trustworthy the research methods undertaken must be consistent with the methodology that underpins and ultimately provides the guiding strategy for the assessment process. 
The methods adopted in assessment focus on the collection of all the materials required by the measures for assessing student learning outcomes. The process varies greatly depending on the measure and type of materials required. Examples could be as varied as e-portfolios, student art, or capstone material. However, as much of the material is course-embedded it will be necessary to coordinate a collection schedule with the faculty involved in order to ensure it is forwarded to the appropriate assessment personnel. In the case of indirect measures (student survey, employer survey, focus group, or other such measures), a schedule that outlines the materials needed and the parties responsible for gathering this material needs to be specified (Clor- Proell, Proell, \& Warfield, 2014). A good assessment technique should be:

1. Valid - It should directly reflect the student learning outcome being assessed i.e. includes everything material that is necessary for a faithful representation of the student learning outcome.

2. Reliable - it should be calibrated to ensure inter-rater reliability i.e. reasonably free from error or bias and faithfully represents what it purports to represent.

3. Actionable - Results identify learning strengths to capitalize on and weaknesses needing to be addressed i.e. the capacity of the information generated to influence a future decision as it relates to SLOs.

\section{Analyze, Evaluate And Interpret Assessment Data For Evidence Of Student Learning Outcomes}

Analysis of data is the next step in the assessment process with an emphasis on utilizing the appropriate method for analyzing the data and the correct tools for its processing. The analysis can range from simple counts and percentages of successful students to advanced statistical analysis. The goal is to record the number of students involved with a particular activity and the success rate relative to the targeted student learning outcomes.

The use of mean, median and mode can easily provide useful information to interpret collected data and allows for an easy comparison between groups and tests as well as having the ability to highlight significant differences. In order to accomplish this it is vitally important to ensure that analysis methods fit the data collected and that methods properly align with the assessed program. Tables and graphs provide a useful way of presenting the analyzed data as they can focus attention on specific results. The strength of tables is the ease of presenting frequencies, percentages and comparing expected student outcome performance to the observed student performance. This presentation can be enhanced with the use of graphs for visualization of the results and are highly effective in showcasing assessment results. The goal is to summarize, compare and display the data in such a way as to provide direction for any decisions regarding program improvement.

In general, there are two types of data used in assessment with each requiring different methods of processing: categorical data and numerical data. Categorical data is based on categories or groupings for the purpose of performance evaluation. Numerical data, conversely, is used in scale-based performance evaluation. In the analysis of performance data, it is important to:

1. Analyze performance differences and its effect on curricular change.

2. Conduct pre-assessment and post assessments (after implementing suggested programmatic changes) for the express purpose of evaluating specific learning outcomes.

3. If possible, compare student outcome results to a national performance average.

The key activity is to compare the results to the success target. Was the success target met? This is an important feature of assessment as you need to have a result for every method/measure you have defined in your assessment plan.

When the data has been analyzed key questions that need to be asked include:

1. What are the valuable insights gained from assessment results?

2. What are the important conclusions that can be drawn from assessment results?

3. What weaknesses (or strengths) in student learning are supported by the assessment results?

4. What do the results suggest about advising, pedagogy and curriculum?

5. What do the results suggest about future programmatic improvement? 
It is not a sign of failure if an Outcome/Objective and the set Achievement Target are not met. The assessment process provides the necessary information needed in order to make informed decisions on what might be done differently to make improvements. That is why assessment should be viewed as a longitudinal multidimensional integrated process rather than a short cut towards institutional legitimacy via an accreditation body.

Write The Yearly Assessment Report And Communicate The Assessment Findings To Those Involved In The Process Of Assessment

This phase is about reporting the results of the assessment process. Here the focus is on identifying and interpreting the strengths of the program, areas that have been identified as needing improvement and finally, making recommendations to improve the student learning process. This can only be accomplished by working with the faculty concerned to correctly understand the results. As Muñoz, Jaime, McGriff, and Molina (2012) and Palomba and Banta (1999) observe faculty are in the classroom and have intimate knowledge of the students and what the learning outcome is trying to measure. After discussions with the faculty, an assessment report is constructed.

A typical assessment report contains the following component parts:

1. Executive Summary which can include:

A. a brief history of previous assessments,

B. a demonstrated linkage to school and university mission statements

2. Outcome Reports by College followed by outcome reports by Program including:

A. Summary of Past Assessment,

B. Current Assessment

C. Activity

D. Interpretation of Results with Recommendations

3. Appendix of supporting materials including:

A. SLO's by program

B. Assignments

C. Rubrics

The authors concur with Middaugh's (2009) observation that it is important that you know the audience for whom the report is intended. That is, who is the audience and what do they need to know. For example, is the report intended for Federal Agencies, College Deans, Curriculum Committees, External Accreditation Bodies or Assessment Personnel? The audience is the key to preparing the report as the audience determines the purpose and focus of the report. An external accreditation body would dictate that the purpose of the report is to make a case for accreditation by highlighting the outcomes of the student learning process whereas, if the report is targeted at College Deans, then the focus would be on ways to improve curriculum changes, course sequencing and so on.

The content and focus of the assessment report should be on addressing the following six questions:

1. What was the approach taken for assessment?

2. Why was this approach taken?

3. What was the method(s) used in accomplishing this approach?

4. What were the results from the assessment process?

5. How will the results be used to improve student learning?

6. How effective was the assessment plan?

In summary, keep the message clear, to the point, and above all focused.

Use Feedback To Implement Changes And Re-Evaluate The Assessment Process With The Intent To Continuously Improve The Quality Of Student Learning; Plan For The Next Assessment Cycle.

Assessment is a cyclical process and builds on previous work and activities. The process of 'closing the loop' requires taking program findings (based on assessment results) and implementing changes needed to improve 
the student learning process. The purpose of assessment is always to help determine the effectiveness of student learning and to allow the documenting of continuous improvement. Achieving the established outcome/objective may not always occur but the goal must be to demonstrate continuous improvement.

Assessment findings, in general, can indicate a need to modify the assessment process or the academic program. It is also possible that the assessment findings reveal that the program being assessed has strengths that can be utilized to improve other student learning outcomes or programs. But, when making changes, take into consideration resource availability, time constraints and institutional culture. However, small incremental changes sometimes make the biggest difference. The goal is not only to improve student learning outcomes, but also to improve the assessment process itself.

All improvements revealed through assessment should be reported provided they are improvements based on assessment findings. Continuous improvement dictates continuous reporting. It shows a dynamic program constantly evolving with the end goal of improving student learning through faculty involvement, community discussion and shared governance.

Any proposed changes will be a part of the improvement plan for the following year thus 'closing the loop'. The improvement plan forms the core of the action plan for the program/college/university. The action plan must answer the following two questions:

1. Specifically, what did the assessments show regarding any outcome/objectives?

2. How will these findings be used to make or support future improvements in your college or program level?

Any proposed changes require documentation for justification and the assessment results will provide the evidence on which to base/justify these changes. That is, any curriculum changes, new faculty, staff hires, funding and resource requests needed to improve effectiveness of student learning will have the appropriate assessment documentation needed to support such requests. Additionally, even negative assessment results can have a powerful impact on resource allocation when they are used to improve performance, effectiveness, and the university's ability to achieve its mission.

Once the above six steps have been completed the process will start all over again in the pursuit of continuous quality improvement.

\section{Who Is Responsible For Developing An Assessment Process For Academic Units?}

Middaugh's (2009) findings that assessment of student learning is a vital part of the mission of any institution and should be consistent with the institution's mission statement and strategic plan are in line with your own assessment of the process. Institutions must foster a culture that assessment of student learning is a shared responsibility among students, faculty and administration. Responsibility for assessment can be divided into three main areas:

1. Program Outcomes Assessment: Faculty and administrative leaders within each school, college, department, program and Assessment Office.

2. General Education Assessment: General Education Committee and Assessment Office.

3. Assessment of Student and Alumni Satisfaction: Division of Undergraduate Studies, Career Services Center, Academic Affairs, Student Life, Alumni Relations, and Assessment Office.

Every academic unit is responsible for defining learning outcomes for their program(s) and establishing a process that outlines:

1. Who collects and reviews assessment data

2. When assessment data is collected and reviewed

3. How assessment data is collected and reviewed

4. What is the most effective process for assessing SLOs? 
Academic units hold primary responsibility for any programmatic design, development, implementation, evaluation and improvement of their programs. With respect to faculty involvement, they are in the best position to define, select and use the measures necessary to assess the SLOs and to use that information to improve them. The best way to accomplish this is for each college/school to have at least one curriculum or assessment committee that is responsible for defining student learning outcomes, reviewing the annual results and developing action plans that can be used to improve student learning outcomes. Additionally, as assessment of student learning goals touches all schools and programs, it should be coordinated by a university-wide Curriculum and Academic Policies Council.

\section{What Is The Role Of The Office Of Assessment In This Process?}

The Office of Assessment (OA) should act as the checkpoint in all things relating to assessment including the monitoring of the data collection process (Driscoll \& de Noriega, 2006). The OA should be involved in the curriculum-development process and all learning goals and rubrics to ensure that:

1. $\quad$ Each goal defines only one primary knowledge area

2. Students can manifest the knowledge and skills required for mastery of the identified student learning outcome by the end of the course for each specific behavior listed

3. All cognitive tasks are appropriate for the level of complexity required and demonstrate mastery

4. All rubrics are reviewed for correctness and alignment with student learning outcomes

Additionally, any new course offerings or revisions to existing courses are subject to review by the OA to ensure that the new course or revision are in alignment with university and program mission statements and that all student learning outcomes are properly aligned with assessment methods.

\section{Assessment Methodology And Method - Key Components Of The Assessment Process}

For the assessment process to be successful it is necessary to determine the assessment methods to be used and the data that will be collected as well as identifying the sources of that data and the approximate timeframe for the assessment period. With respect to assessment in education, it must be impressed upon faculty that there needs to be a culture of teaching and a culture of evidence and for this to occur, the process of learning must be as important at the product of learning (Keeling, 2006).

In general, when determining the assessment methodology focus on the following questions:

1. What type of data will provide the needed information required by the accreditation body?

2. What research design will best provide the required information?

3. How best to display data (comparisons or statistics) to make the best case to the accreditation body?

4. What is the assessment period?

5. How frequently will assessment be done?

6. Who is responsible for data collection?

Some assessment methodologies and methods are better for addressing some types of questions than others.

An effective assessment methodology begins with clarity of focus with respect to what is trying to be accomplished. If the methodology, methods, and expectations of assessment are not clear it makes it almost impossible to convey to faculty what is needed. It is vital to specifically and clearly:

1. Detail the evidence that provides the best representation of the identified learning of interest, how it is gathered and who is responsible.

2. Define the assessment methods used in the assessment of student learning.

3. Ensure that the content of the curriculum is aligned with student learning outcomes.

4. Measure the knowledge and skills graduates are likely to need after graduation 
Guidelines For Developing Assessment Methods

Assessment is geared toward determining whether or not students are learning. That is, are students learning what is expected of them and, based on that answer, what adjustments are the faculty making to enhance student learning? As Wergin (2005) observed the first step in this process is to determine what it is the student is to learn.

\section{Developing Learning Outcomes}

Begin with a clear statement of the identified learning goals and objectives. This will serve as the foundation for the plan of assessment. The learning outcomes shape the type of questions asked which in turn suggests the most appropriate assessment methods to be employed and ultimately will determine how useful the assessment results will be for making programmatic changes.

\section{$\underline{\text { Identify Goals }}$}

A goal is expressed/defined in terms of broad learning outcomes and concepts (what is it that you want the students to learn) and written in general terms. This is often referred to as a Learning Objective. For example: "Students will have an understanding of the major concepts in the field of Metaphysics". After outlining the overall view of what the student should learn from the program, proceed to the next step of identifying the specific skill needed for that learning to take place.

\section{Identify Outcomes}

An 'outcome' is the specific skill, value, or attitude students should demonstrate and is reflective of the broader goals. This is often referred to as a Student Learning Outcome and reflects what the student actually learns. The general format for writing a Student Learning Outcome is:

1. the 'target'
2. 'action verb'
3. 'modifiers'

An excellent way of creating behavior-based learning outcomes is to use Bloom's (1956) taxonomy and classification system (refer figure 2). Bloom created a classification system of increasing levels of cognitive behavior and their associated action verbs to denote learning. For example:

Students can evaluate the validity and limitations of scientific claims with respect to consciousness and its existence after death.

In this example a stated general goal has been transformed into a specific student performance with the appropriate behavior sought that demonstrates the expected student learning skill. Remember - goals and outcomes are similar. As noted by Bresciani (2006) both describe the intended purpose and some expected result due to assessment. However:

1. Goals are general statements about aims or purposes of a program.

2. An outcome is a concise clear statement describing the desired specific student behavior, skill or abilities identified as critical for student success that is observable and measurable. 
Figure 2. Bloom's (1956) Taxonomy And Selected Associated Descriptors Modified By Garfolo Phelps, \& Klepsh (2014)

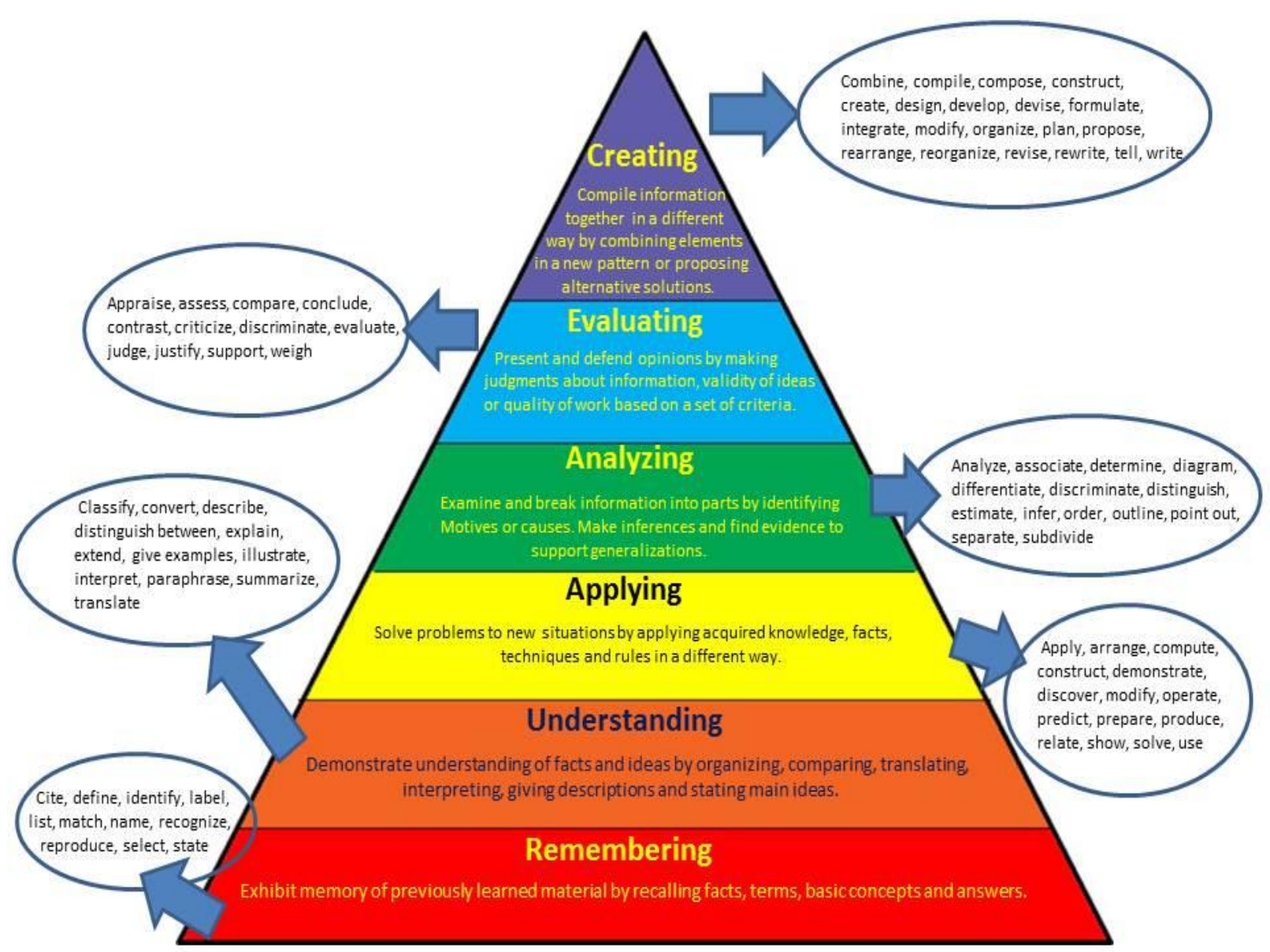

The expected learning outcome for a student refers to specific knowledge, attitudes, practical and higherorder thinking skills that the student is expected to master. It is a clear statement of what is expected, focuses on measurable performance and makes clear the intended learning. It provides the student with a well-defined and precise statement of what is expected.

For a Student Learning Outcome to be effective, it must possess three characteristics:

1. Behavior - The competency to be learned in performance terms. Use a strong action verb to identify the observable objective.

2. Criterion - How the performance will be judged.

3. Conditions - Under what conditions will the learner perform the observable objective.

Without clear learning goals, it is not possible to specifically define learning objectives (what students must know and do to meet the goal). Additionally, without specific learning objectives, gathering meaningful data on the task being measured is not possible. This is why clear and specifically defined Student Learning Outcomes are at the heart of the assessment process. 


\section{Create Curriculum Maps}

A curriculum map ${ }^{l}$ is used to graphically represent how a degree program's learning outcomes are addressed. A curriculum map is a matrix that provides a visual representation of:

1. a program's curriculum

2. the linkage of each identified Student Learning Outcome (SLO) to courses

3. what the position of the course is in terms of program sequence

4. whether the SLO is Introduced, Reinforced, Mastered or Assessed in the course and the assignment that is used to assess the particular SLO

It is not unusual to find courses in a program that do not contribute to any identified learning outcome. A curriculum map visually displays the learning objectives addressed, how it is aligned to the curriculum and if the student is given multiple opportunities to master a particular learning outcome. Used correctly curriculum maps can be useful in identifying gaps in student learning which then allows faculty to make improvements for student learning. The benefits of curriculum maps include:

1. Revealing gaps in the curriculum

2. Improved communication with faculty about the curriculum and linkages between courses

3. Better curriculum sequencing

4. Increases the likelihood that students achieve program level outcomes

5. $\quad$ Aids in assessment plan design

6. Helps faculty understand what skills their course builds on and what the next course in the sequence expects

7. Identifies opportunities for assessment

\section{Specify Approaches}

During this part of the process it is necessary to define/identify the data collection method. For example, capstone courses, portfolios, external reviews, standardized exams, or internships? It is important that multiple approaches are identified. As noted by Wright (2004) students have more than one way of learning, so it is important to specify more than one way of information gathering to ensure that the student has ample opportunity to demonstrate their learning. Careful consideration needs to be given to the following during this stage of the process:

1. Are faculty involved and willing to participate?

2. Will all students be evaluated or only a representative sample?

3. What is the impact on student and faculty workloads for the proposed assessment?

4. Which approach to information gathering will be employed - cross-sectional or longitudinal?

5. Will this be a quantitative or qualitative assessment or employ elements of both?

\section{Assessment Methods And Instruments}

There is no single 'perfect' assessment instrument capable of capturing the complexities and nuances of student learning. At a minimum two methods of assessment for each student learning outcome should be utilized. For example, it would be necessary to have one benchmark assessment given at the beginning of the year and a second, different, assessment towards the end of the year to assess the growth of student learning and the discovery of any relevant patterns of learning. As such exams, presentations and assignments should be part of the normal curricular process of student evaluation not something added specifically for assessment. The evidence collected is largely dependent on the question(s) that need to be answered (Fair Test: The National Centre for Fair and Open Testing, nd).

\footnotetext{
${ }^{1}$ A curriculum map is sometimes referred to as an 'IRMA' map where $\mathrm{I}=$ introduced; $\mathrm{R}=$ reinforced; $\mathrm{M}=$ mastered; $\mathrm{A}=$ assessed.
} 


\section{Designing Outcome Measures}

Measures represent the specific instruments used to provide data. It is necessary to specify the tools and methods for gathering the data that will confirm whether or not student learning has taken place.

\section{Specifc Measures}

Selection of outcome measures is the next step in the assessment process. A learning outcome describes the knowledge, skills and abilities a student should possess when instruction/program is completed. An outcome measure, however, refers to the tools and methods used for data and information generation with respect to students' performance. Select the appropriate assessment method that reflects the programs' goals and objectives. Each method provides information but has its own limitations, so best practice in an ideal assessment program would be to combine methods to develop a clearer picture of student learning. The measure chosen needs to provide the necessary data/information to measure the learning outcome, be easy to collect and have benchmark performance standards to measure results against, which will help guide the analysis. Generally, outcome measures fall into two types: direct and indirect measures of assessment.

Direct Measures - Direct methods of assessment require students to produce a sample of their actual work that can be evaluated and assessed to determine how well students meet expectations. This would include exams, reports, and performances. Some people call this type of measure 'authentic' measures of assessment.

Indirect Measures - An indirect measure, by contrast, refers to assessment that measures opinions about students' knowledge, skills, and attitudes through such tools as internship supervisor reports, job evaluations, and alumni survey. It is perceived student learning, not actual direct assessment of student learning. Indirect measures are helpful from the standpoint of interpreting the findings of a direct method of assessment but offer no concrete reporting of specific success or failure of a learning outcome.

\section{$\underline{\text { Advantages and Disadvantages of Potential Assessment Methods }}$}

The advantage of direct measurement of assessment is that they are usually embedded in course assignments. Faculty members immediately capture a sample of what students can do and as such are able to gauge to what extent learning has taken place. This can easily be demonstrated by the use of exams, standardized exams, and quizzes. However, a weakness of direct measurement of assessment is that 'one size does not fit all'. Not everything can be demonstrated in a direct way, such as attitudes, values, and perceptions. Additionally, as many tests are constructed of multiple-choice or true-false questions, students guessing and strategizing over answer choices can tend to measure their test-taking skills and not mastery of the concepts the test was designed to measure.

The advantage of indirect measurement of assessment is that they prove to be effective measures of the effectiveness of a program. Quite quickly it is possible to determine if the 'message' of the program is getting through to the student. Indirect measures of assessment include surveys and opinion polls. It provides information with respect to quality and motivation of learning. However, a weakness of indirect measurement of assessment is that it does not provide any specific evidence that actual student learning has occurred. It is more a measure of perceived learning. Additionally, it is easier to 'fake' responses on indirect measures of assessment and it tends to measure breadth of learning not depth of learning.

Indirect assessments can be personal. Here the students report how they feel about learning and their learning experience. That is, their opinion or self-analysis of their experience or value of the learning process. Indirect assessment data comes through reflection of learning rather than demonstrated direct evidence of learning. Examples of indirect assessments are surveys (alumni, student, and employee), questionnaires, interviews, and focus groups.

Educators can use both direct and indirect assessment approaches to provide useful information in improving student learning. Each can identify strengths and weaknesses in the student. However, no one measure is adequate; the measures show complementary advantages and disadvantages with respect to assessment of student 
learning. A combination of the two methods presents a more comprehensive view of the effectiveness of student learning.

How To Choose An Assessment Method And Develop An Assessment Instrument

Assessment needs to be:

1. Measurable

2. Manageable

3. Meaningful

4. Sustainable

5. Simple

When choosing an assessment method, it is important to consider a variety of factors, for example, alignment with the student learning outcome and ease of scoring. Appropriate strategies can only be determined by fully involving the faculty, consideration of the skill to be assessed, the level of its assessment and the context for its assessment. Careful consideration should be given to embedding assessment in benchmark assignments throughout the curriculum so that the performance assessed properly reflects the best measure of the desired student learning outcome. There needs to be a strong relationship between the course and the associated content to be assessed when attempting to embed assessment into existing coursework.

One of the most important things to consider when choosing or developing an assessment method is the alignment of the student learning outcome with its instrument of measurement. This may seem obvious, but it is not uncommon to see a misalignment between the outcome and the assessment instrument. For example, having the assessment based on the student making a presentation when teaching a research methodologies course may not be a good measure of this student learning outcome.

When determining assessment methods, remember to:

1. Be selective; the assessment data collected should depend on the type of questions needing answers.

2. Use multiple methods to assess each student learning outcome. Include:

A. qualitative measures

B. quantitative measures

3. Choose benchmark assignments for assessment to establish baseline criteria

Scoring Instruments

Performance-based education poses a challenge in identifying and assessing critical tasks that focus on the students' ability to use the knowledge and skills deemed critical to demonstrate student learning. In performanceassessment, a scoring instrument is used to assist the evaluator in scoring student performance consistently and objectively. Scoring instruments include: checklists, rating scales and rubrics (holistic and analytical). These tools have varying degrees of criteria and enable the gathering of information for the purpose of making judgments about the success or failure of student learning with respect to specific outcomes.

Scoring instruments can be grouped into three general categories:

1. Checklists

2. Basic Rating Scales

A. Numerical Rating Scales

B. Graphic Rating Scales

3. Rubrics

A. Holistic Rating Scales

B. Analytic Rating Scales 


\section{$\underline{\text { Rubrics }}$}

Basic checklists and rating scales are straightforward and can be used in assessment but offer limited ability to assess complex tasks. A traditional two-dimensional rubric offers more flexibility in assessing a specific outcome. In general, a rubric is composed of four basic parts:

1. A description of the task being assessed.

2. $\quad$ Each characteristic to be rated (rows).

3. Mastery level of the task (columns).

4. A description for each characteristic at each level of mastery (cells)

Rubrics offer systematic ways of collecting data about specific knowledge, skills and behaviors. Their effectiveness is based on the quality of the descriptors chosen and the subject matter experts used in their development. Fundamentally, a rubric articulates the criteria for each identified learning outcome and contains a gradient of performance descriptors indicating level of mastery for the specific outcome being assessed.

A rubric provides several advantages for assessment including:

1. Can be used to assess virtually any behavior, performance, essay, research, presentation, individual or group project.

2. Provides timely and clear feedback to students so that they can monitor their progress toward clearly stated goals

3. Encourages critical thinking

4. Facilitates communication between faculty and students

5. Helps faculty to improve teaching skills

There are two main types of rubrics - analytical and holistic, the difference being the number of discrete criteria addressed in the rubric. That is,

1. Holistic rubrics do not separate levels of performance for each of the identified criteria. They 'lump' them together so that the level of performance is assessed over multiple criteria. A holistic rubric gives more of an overview of learning.

2. Analytical rubrics articulate levels of performance over discrete criteria. That is, each individual component of the learning outcome can be assessed independent of any other criteria. An analytical rubric allows for the focusing on a specific aspect of the learning assessed to indicate the level of mastery.

The choice of using a holistic or analytical rubric is determined by the depth and breadth of the question the rubric was designed for. However, regardless of the rubric type, the key to developing an effective rubric is to use clear criteria that evaluates the performance identified and is directly observable. Without this capability, the scores on the performance task cannot offer meaningful data on learning, growth or achievement.

\section{Closing The Loop' In The Outcomes Assessment Process}

'Closing the loop' means:

1. Analyzing the data

2. Deciding what course of action to take based on findings such as pedagogy, course structure, or assessment process.

3. Documenting findings, proposed improvements/changes and the rationale that underpins these proposed improvements/changes.

Assessment is cyclical in nature and each cycle builds upon previous work. To 'close the loop' requires recommendations (based on findings) be put into practice to see if it improves student learning (Zull, 2002). 


\section{Assessment Report}

The purpose of academic assessment is to provide a systematic way of gathering and analyzing data in an explicit and transparent way in order to provide evidence to demonstrate that students have accomplished the learning objectives. That is, are students learning what you say they are learning and can you supply corroborating evidence?

Analysis of data, conclusions reached and recommendations made are stated in the assessment report. The audience for this report plays a critical role in the format and presentation of information. For example, is the report for accreditation purposes (each accrediting body has their own requirements), state or federal funding, alumni, faculty/curriculum planning committees? However, regardless of the target audience at a minimum the report must address the following four questions:

1. What was done to assess student learning (what was the process)?

2. Why was student learning assessed in this way (rationale for picking programs, SLO's, time frame)?

3. What was revealed as a result of the assessment (analysis of findings with respect to student learning or the assessment process in general)?

4. What will happened based on this information (communicate and replicate best practices or identify areas of concern for improving student learning)?

Assessment helps to determine effectiveness with respect to student learning. Continuous improvement for each learning objective may not be achievable but it is possible to demonstrate continuous improvement in learning. Furthermore, negative assessment results can be a powerful motivating force on an administration that is reluctant to embrace change or provide additional resources. In the authors experience, nothing motivates an organization's administration quite like a negative accreditation report, regardless of whether it is internally generated or from an external reporting agency.

Once recommendations have been made it is then necessary to create an action plan to put them into effect. The action plan will have a review mechanism built into it to determine whether the implemented recommendations have made a difference in student learning. This, in effect, is the tail end of 'closing the loop' and forms the beginning of the next assessment cycle.

\section{CONCLUSION}

Accreditation is a voluntary process of self-regulation and non-governmental peer review. The education community, in general, supports and legitimizes it so that institutions can state that they possess sound educational practices and the ability for improvement through regular assessment, planning, change and reassessment. In essence, accreditation provides a benchmark for quality and integrity. The process of accreditation examines the philosophy, goals, programs, facilities, resources and financial viability of institutions.

Even though the federal government is not directly involved with accreditation, it is through accreditation that an institution becomes eligible to participate in both state and federal financial assistance programs. Accreditation fulfills its purpose by providing the transparency that the public wants while ensuring the quality of the product they produce namely the student graduate.

There are two basic types of accreditation: Institutional and Specialized. With institutional accreditation, the accrediting body looks at the institution in its entirety. With respect to specialized accreditation, there are a multitude of accreditation bodies depending on the area of specialization - each responsible for accrediting program quality in their area of specialization. Specialization accreditation standards are above those required for institutional accreditation. 
Accreditation serves many functions including the following:

1. Establishes criteria for successful learning at the undergraduate, graduate and professional levels

2. Aids in establishing transfer of credits between institutions

3. Identification of peer-reviewed institutions meeting established quality criteria

4. Involves faculty in program and course planning, review and potential program improvement or elimination

5. Potentially provides the ability to access State and Federal financial assistance

6. Assures the public that graduates from an accredited school have received quality instruction

7. It ensures that the institution maintains a culture of aiming for excellence and continuous improvement.

8. Provides the student with an assurance of educational quality which is recognized by other learning institutions and the employment sector.

Accrediting bodies still, however, fall short in some areas including:

1. There is no requirement for statistics on student success in terms of graduation rates, retention rates, employment rates of recent graduates and transfer rates to be made publically available.

2. There is no requirement for published benchmarks for quality and quality improvement, shorter review cycles (eliminate cycles greater than three years), or clear progressive penalties for institutions that do not meet these benchmarks.

3. Accrediting bodies need greater accountability themselves in reporting their own findings about how the accreditation process affects academic performance across institutions.

The authors overall recommendation for you on your road to accreditation: Do not try to overly complicate the process or the information you provide.

\section{AUTHOR INFORMATION}

Blaine Thomas Garfolo, $\mathrm{PhD}$, is an emeritus Associate Professor and currently serves as Chair of the DBA Advisory Committee at Northwestern Polytechnic University and is an Assessment Coordinator at the University of Phoenix in the Office of Assessment. He has taught internationally in Australia and New Zealand and was chair of Faculty Research in the COB at Prince Mohammad bin Fahd University, Saudi Arabia. He presents and publishes nationally and internationally in the fields of Assessment, Business, Psychology, Philosophy and Metaphysics. Email: bgarfolo@gmail.com.

Dr. Barbara L'Huillier currently serves as Associate Chair for the Department of Accounting and Finance at Prince Mohammad Bin Fahd University, Saudi Arabia. She is an accountant by 'trade', initially working in public practice before turning to teaching. Theoretical direction for her doctoral and post-doctoral research comes from critical theory and the use of power for transformational intent. She is an accomplished poet and has numerous poems published (or in press) in refereed accounting journals. She is particularly interested in notions of justice, equity and 'good' governance, ethics, globalization and accreditation. Email: blhuillier@pmu.edu.sa.

\section{REFERENCES}

Allen, M. J. (2004). Assessing academic programs. Boston: Anker Publishing.

Ali-Mohamed, A. Y. (2008). Accreditation of learning institutions. In Al-Hawaj, Elali \& Twizzell (Eds.), Higher Education in the twenty-First Century: Issues and Challenge (pp. 71-83). London: Taylor \& Francis Group.

American Association for Higher Education. (1998). Nine principles of good practice for assessing student learning: American Association for Higher Education Assessment Forum. Retrieved from: http://www.aahe.org/assessment/principl.htm

Anderson, L. W., Krathwohl, D. R., Airiasian, W., Cruikshank, K. A., Mayer, R. E., \& Pintrich, P. R. (2001). A taxonomy for learning, teaching and assessing: A revision of Bloom's Taxonomy of educational outcomes: 
Complete edition. New York: Longman.

Angelo, T. A. (1995a). Improving classroom assessment to improve learning: Guidelines from research and practice. Assessment Update, 7(6), 1-2.

Angelo, T. A. (1995b). Reassessing (and defining) assessment. AAHE Bulletin, 48, 7-9.

Angelo, T. A. (1999). Doing assessment as if learning matters most. AAHE Bulletin, 51(9), 3-6.

Angelo, T. A., \& Cross, K. P. (1993). Classroom assessment techniques: A handbook for college teachers (2 ${ }^{\text {nd }}$ ed.). San Francisco, CA: Jossey-Bass.

Astin, A. W. (2012). Assessment for excellence: The philosophy and practice of assessment and evaluation in higher education. Maryland: Rowman \& Littlefield Publishers.

Banta, T. W. (Ed.). (2002). Building a scholarship of assessment. San Francisco, CA: John Wiley \& Sons.

Banta, T. W., Jones, E. A., \& Black, K. E. (2010). Designing effective assessment: Principles and profiles of good practice. San Francisco, CA: John Wiley \& Sons.

Black, P., \& Wiliam, D. (1998). Inside the black box: Raising standards through classroom assessment. London: Granada Learning.

Blaich, C., \& Wise, K. (2009). Hampshire and Wabash assessment collaborates review. Retrieved from: http://www.liberalarts.wabash.edu/storage/Assessment_Collaborative_Review.pdf.

Bloom, B. (1956). A taxonomy of educational objectives: The classification of educational goals. Handbook I: Cognitive domain. New York, NY: David McKay Company.

Bloom, B. S., Englehart, M. B., Furst, E. J., Hill, W. H., \& Krathwohl, D. R. (1956). Taxonomy of Educational Objectives: The classification of educational goals. Handbook 1: Cognitive Domain. New York City: Longman.

Boud, D. (1995). Assessment and learning: contradictory or complementary. In P. Knight (Ed.), Assessment for learning in higher education, (pp. 35-48). London: Kogan Page.

Bresciani, M. J. (2006). Outcomes-based academic and co-curricular program review: A compilation of institutional good practices. Sterling, VA: Stylus Publishing, LLC.

Bresciani, M. J., Zelna, C. L., \& Anderson, J. A. (2004). Assessing Student Learning and Development: A Handbook for Practitioners. Washington, D.C.: National Association of Student Personnel Administrators.

Brookhart, S. M. (1999). The Art and Science of Classroom Assessment. The Missing Part of Pedagogy. ASHEERIC Higher Education Report, 27(1). ERIC Clearinghouse on Higher Education, Washington, DC.

Coffey, J., Black, P., \& Atkin, J. M. (Eds.). (2001). Classroom assessment and the national science education standards. USA: National Academies Press.

Clor-Proell, S. M., Proell, C. A., \& Warfield, T. D. (2014). The Effects of Presentation Salience and Measurement Subjectivity on Nonprofessional Investors' Fair Value Judgments. Contemporary Accounting Research, $31(1), 45-66$.

Curry, R. A., \& Gonzalez-DeJesus, N. T. (2010). A literature review of assessment: what new sonographic faculty should know. Journal of Diagnostic Medical Sonography.

Driscoll, A., \& de Noriega, D. C. (Eds.). (2006). Taking ownership of accreditation: Assessment processes that promote institutional improvement and faculty engagement. Virginia USA: Stylus Publishing.

Driscoll, A., \& Wood, S. (2007). Developing outcomes-based assessment for learner-centered education: a faculty introduction. Virginia USA: Stylus Publishing.

Dugan, R.E., and Schwartz, C. (Eds.). (2006). Revisiting outcomes assessment in higher education. Westport, CT: Libraries Unlimited.

Elkins, B., Morris, K., \& Schimek, G. (2013). Making Meaning through Multicultural Initiatives. New Directions for Student Services, 2013(144), 17-26.

Fair Test: The National Centre for Fair and Open Testing (n.d.). Fact Sheets. Retrieved from http://www.fairtest.org/univ/univfactsheets.htm.

Garfolo, B. T., Phelps, Y., \& Klepsh, E. (2014). Programmatic Assessment: The Road to Accreditation. Honolulu, Hawaii: $13^{\text {th }}$ Annual International Conference on Education.

Glaser, R., Chudowsky, N., \& Pellegrino, J. W. (Eds.). (2001). Knowing What Students Know: The Science and Design of Educational Assessment. USA: National Academies Press.

Gonzalez, K. P., \& Padilla, R. V. (1999). Faculty Commitment and Engagement in Organizational Reform. Higher Education, 13, 29-45.

Gronlund, N. E. (1998). Assessment of student achievement. Boston: Allyn \& Bacon Publishing.

Hernon, P., \& Dugan, R. E. (Eds.). (2004). Outcomes assessment in higher education: Views and perspectives. 
Westport, CT: Libraries Unlimited.

Hersh, R. H. (2007). Collegiate learning assessment (CLA): Defining critical thinking, analytical reasoning, problem solving, and writing skills. Retrieved from www.minotstateu. edu/pio/inside/2007_10_17. Pdf.

Huba, M. E., \& Freed, J. E. (2000). Learner centered assessment on college campuses: Shifting the focus from teaching to learning. Community College Journal of Research and Practice, 24(9), 759-766.

Hutchings, P. (2010). Opening doors to faculty involvement in assessment. NILOA Occasional Paper, (4).

Ivanovski, Z., Milenkovski, A., Ivanovska, N., \& Kozuharov, S. (2013). Development and Improvement of Business Higher Education Through Implementation Of Students Learning Outcomes Assessment Plan (Sloap). UTMS Journal of Economics, 4(1), 1-16.

Keeling, R.P. (Ed.). (2004). Learning Reconsidered: A Campus-wide Focus on the Student Experience. Washington, D.C.: American College Personnel Association

Keeling, R.P. (Ed.). (2006). Learning Reconsidered 2: Implementing a campus-wide focus on the student experience. Washington, D.C.: American College Personnel Association.

Kuh, G. D., \& Ikenberry, S. O. (2009). More than you think, less than we need: Learning outcomes assessment in American higher education. Champaign, Illinios: National Institute for Learning Outcomes Assessment.

L'Huillier, B. M. (2012). Making Meaning, Governing Change: Wittgenstein meets Humpty Dumpty. European Journal of Business and Social Science, 1(6), $124-139$.

Lpez, C. L. (2002). Assessment of student learning: Challenges and strategies. The Journal of Academic Librarianship, 28(6), 356-367.

Maki, P. (2002). Using multiple assessment methods to explore student learning and development inside and outside of the classroom. American Association for Higher education: NASPA.

Middaugh, M. F. (2009). Planning and assessment in higher education: Demonstrating institutional effectiveness. New York: John Wiley \& Sons.

Miller, M. A. (1997). Looking for results: The second decade. In American Association for Higher Education (Ed.), Assessing impact: Evidence and action (pp. 23-30). Washington, DC: American Association for Higher Education.

Miville, M. L., Gelso, C. J., Pannu, R., Liu, W., Touradji, P., Holloway, P., \& Fuertes, J. (1999). Appreciating similarities and valuing differences: The Miville-Guzman Universality-Diversity Scale. Journal of Counseling Psychology, 46(3), 291.

Muñoz, E. A., Jaime, A. M., McGriff, D. L., \& Molina, A. H. (2012). Assessment of Student Learning Estudios Chicana/o Cultivating Critical Cultural Thinking. Teaching Sociology, 40(1), 34-49.

Palomba, C. A., \& Banta, T. W. (1999). Assessment Essentials: Planning, Implementing, and Improving Assessment in Higher Education. Higher and Adult Education Series. San Francisco, Jossey-Bass Publishers.

Resources (n.d.). In Council for the Advancement of Standards in Higher Education. Retrieved from: www.cas.edu

Suskie, L. (2010). Assessing student learning: A common sense guide ( $2^{\text {nd }}$ ed.). New York: John Wiley \& Sons.

Upcraft, M. L., \& Schuh, J. H. (2002). Assessment vs. Research: Why We Should Care about the Difference. About Campus, 7(1), 16-20.

Walvoord, B. E., \& Anderson, V. (1995). An assessment riddle. Assessment Update, 7(6), 8-11.

Walvoord, B. E., \& Anderson, V. J. (2011). Effective grading: A tool for learning and assessment in college. New York: John Wiley \& Sons.

Wergin, J. F. (2005). Taking responsibility for student learning: The role of accreditation. Change: The Magazine of Higher Learning, 37(1), 30-33.

Wiggins, G. (1993). Assessment: Authenticity, context, and validity. Phi Delta Kappan, 75(3), 200-208.

Wright, B. (2004). More art than science: The post-secondary assessment movement today. Elements of Quality Online Education: Into the Mainstream, 5, 185-197.

Zull, J. E. (2002). The art of changing the brain: Enriching teaching by exploring the biology of learning. Virginia USA: Stylus Publishing. 
NOTES 